DOI 10.30612/re-ufgd.v7i13.10811

\title{
PRÁTICAS DE EXTENSÃO NA OLERICULTURA ORGÂNICA EM DOURADOS-MS
}

EXTENSION PRACTICES OVER ORGANIC OLERICULTURE IN DOURADOSMS

\author{
Mariana Zampar Toledo ${ }^{1}$ \\ Emanuel Barbosa dos Santos ${ }^{2}$ \\ Estevão Honorato Lemes de Paula² \\ Gabriela Aparecida Rigato ${ }^{2}$ \\ Hevelin Fernandes Romeiro ${ }^{2}$ \\ Higor Perikles Guedes Jorge ${ }^{2}$ \\ Keila Garcia Franco ${ }^{2}$ \\ Lorenzo Luis Hoefling Manzoni² \\ Luiz Carlos da Silva Saracho ${ }^{2}$ \\ Roberto Cesar Dobler Filho ${ }^{2}$ \\ Thainá Melina Felipus ${ }^{3}$
}

Resumo: A extensão rural como ferramenta de transformação econômica e social contribui com a melhoria dos sistemas de produção agropecuária por meio das ações de incentivo à sustentabilidade das comunidades no campo. O desenvolvimento de projetos para aplicação prática da extensão fortalece os vínculos entre a universidade e a comunidade rural, além de beneficiar ambos com rica troca de conhecimento e experiências. Nesse sentido, este trabalho objetivou organizar um evento de extensão a partir das demandas levantadas nas propriedades rurais dos associados da Agrovargas $\ddot{i}$ Associação de Produtores de Vila Vargas, em Dourados-MS. Ferramentas do diagnóstico rural participativo $\ddot{I}$ DRP foram aplicadas em duas propriedades com foco na produção orgânica de hortaliças para, em seguidas, definir-se os temas abordados em um dia de campo. Na prática, demonstrou-se o preparo de caldas visando ao controle fitossanitário em sistemas orgânicos e a técnica da compostagem, tanto caseira como em leiras. Adicionalmente, foram apresentadas aos produtores opções de cultivos não convencionais que agregam valor ao seu sistema de produção, quais sejam a araruta, o gengibre, a ora-pro-nobis, açafrão e o taro. A difusão dos conteúdos explorados na ação de extensão gerou impacto positivo na comunidade. Nesse sentido, percebe-se que as

\footnotetext{
${ }^{1}$ Docente da Faculdade de Ciências Agrárias, FCA/UFGD, Dourados-MS.

${ }^{2}$ Graduando da Faculdade de Ciências Agrárias, FCA/UFGD, Dourados-MS.

${ }^{3}$ Graduanda da Faculdade de Engenharia, FAEN/UFGD, Dourados-MS.
} 
ações que integram o ensino e a extensão contribuem sobremaneira para a melhoria do sistema de produção orgânica de hortaliças no âmbito da agricultura familiar.

Palavras-chave: Extensão rural, Fitossanidade, Compostagem, PANC.

Abstract: Agricultural extension as a tool for economic and social transformation contributes to enhancing production systems through actions to encourage sustainability of rural communities. Developing projects to effectively put extension into operation may strengthen ties between the University and rural community, besides mutual benefits of knowledge and experience sharing. In this context, this research had the objective of organizing an event of extension from all demands studied in rural properties of the members of Agrovargas ï Vila Vargas Organic Producers Association, in Dourados-MS, Brazil. Tools of the đ́articipatory rural appraisalô were applied in two properties of organic olericulture to further establishment of the themes to be shown in a field day. In practice, preparation of organic mixtures and two types of composting processes were demonstrated. Additionally, producers could learn about non-conventional species to adding value to their systems, such as arrowroot, ginger, Pereskia aculeata, saffron and yam. Disseminating knowledge through the extension field event generated great and positive impacts on the community. Hence, it was clear that the interaction between Education and Extension deeply contribute to enhancing organic olericulture production of family farmers.

Key words: Rural extension, Plant health, Composting, Non-conventional food plant.

\section{INTRODUÇÃO}

A agroecologia é uma ciência, surgida no final da década de 1970, como forma de estabelecer uma base teórica para os diferentes movimentos de agricultura não industrial (ASSIS, 2005), que procura utilizar o que há de mais avançado em tecnologia para criar agroecossistemas sustentáveis e de alta produtividade, que apresentem características mais semelhantes quanto seja possível às dos ecossistemas naturais (GLIESMAN, 2000). Dentro das vertentes da agroecologia, diferentes formas de abordagem surgiram como movimentos contrários ao modelo agroquímico, como a agricultura orgânica (JESUS, 1985). Agricultura orgânica é um sistema de manejo sustentável da unidade de produção, com enfoque sistêmico que privilegia a preservação ambiental, a agrobiodiversidade, os ciclos biológicos e qualidade de vida do homem, visando à sustentabilidade social, ambiental e econômica no tempo e no espaço (NEVES et al., 2000).

A principal razão do crescimento exponencial do mercado de produtos orgânicos observado atualmente são as novas demandas, por parte dos consumidores, por alimentos saudáveis, nutritivos e seguros, com garantia de origem, enquanto aumentam também as exigências por produtos oriundos de processo ambiental e socialmente corretos (NEVES;

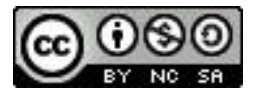


NEVES, 2007). No entanto, com oferta inconstante e aparência inferior dos produtos ofertados, produtores se sustentando com dificuldade na atividade e carência de assistência técnica, a agricultura orgânica terá que ser constantemente avaliada quanto ao seu custo e benefício, nos níveis individual e social, tendo-se em vista os desafios do dinamismo do mercado globalizado e as mudanças climáticas que ameaçam ainda mais a sanidade das plantas, já tão complexa de ser mantida em um país de clima tropical. Além disso, a agricultura orgânica deve assumir o convívio com a também crescente onda de produção integrada, que prevê o uso racional de agrotóxicos, a oferta de maiores volumes e com menores preços (LOPES, 2012).

Embora seja um setor em plena expansão, a produção de hortaliças orgânicas está sujeita a inúmeros riscos. Além daqueles inerentes à agricultura convencional, verifica-se uma baixa escala de produção, limitações quanto à mão de obra, questões relacionadas ao processo de certificação, maior um risco de mercado (LIMA, 2005).

Do ponto de vista produtivo, alguns entraves são constantes na atividade, como as dificuldades quanto ao manejo de adubação e tratos fitossanitários. Segundo as diretrizes no Ministério da Agricultura, Pecuária e Abastecimento, a legislação brasileira da produção orgânica dá tratamento diferenciado aos insumos destinados à agricultura orgânica (BRASIL, 2019).

O manejo do solo deve considerar, além dos aspectos químicos e físicos, os processos biológicos que devem ser estimulados, de modo a garantir o equilíbrio do sistema, através de práticas que contribuam para a manutenção da matéria orgânica (NEVES, 2005). Entre as técnicas mais utilizadas na produção orgânica, a compostagem possibilita utilizar recursos locais, bem como subprodutos orgânicos que proporcionem o fornecimento de nutrientes, de forma ampla e diversificada, priorizando a ciclagem de nutrientes por meio de restos culturais, compostos e resíduos orgânicos e adubações verdes com leguminosas ou plantas espontâneas (LIMA et al., 2011).

Agrotóxicos ou afins são considerados produtos de baixo impacto ambiental e baixa toxicidade, e, por apresentarem em sua composição apenas produtos permitidos na legislação, recebem, após o devido registro, a denominação de ñprodutos fitossanitários com uso aprovado para a agricultura orgânicaò (BRASIL, 2019). De acordo com Lopes (2012), não são claros os critérios do que pode ou não pode ser usado na agricultura orgânica para o controle de praga e doença, sobretudo na atual conceituação de 
agrotóxicos e na definição de produtos fitossanitários com uso aprovado na agricultura orgânica, entenda-se bem, respeitando-se os aspectos filosóficos que norteiam as agências certificadoras.

A integração de práticas culturais é a principal ferramenta para o controle de pragas e doenças em sistemas orgânicos de produção; no entanto, quando não for capaz de evitar a ocorrência e contenção em nível tolerável, são necessárias medidas emergenciais como o controle biológico através da introdução massal de predadores e parasitoides de insetos-pragas ou de antagonistas a fitopatógenos, específicos para cada caso; o uso de bioinseticidas à base de fungos, bactérias ou vírus. Adicionalmente, os preparados caseiros podem ser incluídos no manejo das culturas como as caldas bordalesa e sulfocálcica, admitidas na legislação nacional afeta à agricultura orgânica.

Apesar das técnicas existentes para possível aplicação na produção orgânica, os conhecimentos gerados em instituições de pesquisa, muitas vezes, não chegam ao campo. Diante disto, a extensão tem um papel fundamental para a democratização do acesso às informações essenciais para o produtor, que irá promover a aplicação de resultados atuais de pesquisas na prática, observando os seus resultados alcançados (OLIVEIRA et al., 2012; 2016). Neste contexto, a extensão rural nas Universidades tem o grande desafio de acessar os produtores (PEIXOTO, 2008; GABRIEL et al., 2015) e, ao promover um diálogo horizontal e troca de conhecimento e experiências, propiciar o fortalecimento do desenvolvimento rural.

Neste contexto, o presente trabalho objetivou promover uma ação de extensão para possibilitar a troca de conhecimento e a demonstração de técnicas de compostagem e controle fitossanitário de pragas e doenças na olericultura orgânica em uma comunidade em Dourados-MS.

\section{MATERIAL E MÉTODOS}

A ação de extensão foi desenvolvida no Distrito de Vila Vargas e no Horto de Plantas medicinais, da Faculdade de Ciências Agrárias, da Universidade Federal da Grande Dourados, FCA/UFGD, em Dourados-MS, com o apoio da Agência de Desenvolvimento Agrário e Extensão Ruralï AGRAER/MS. A ação, intitulada ñ Dia de Campo de Extensão Ruralò foi realizada em 2019, pelos acadêmicos do curso de Agronomia, sendo vinculada ao Núcleo de Práticas Extensionistas de Desenvolvimento 
e Integração, PROEX/UFGD. O público alvo consistiu dos produtores associados à Agrovargas - Associação dos Produtores de Vila Vargas, em Dourados-MS.

$\mathrm{Na}$ primeira fase da ação, realizou-se uma visita técnica em duas propriedades aleatoriamente selecionadas, cujos produtores eram associados à Agrovargas. Durante as visitas, foram utilizadas ferramentas do Diagnóstico Rural Participativo (DRP) na identificação de problemas e obstáculos ao sucesso da produção. O DRP pretende desenvolver processos de pesquisa a partir das condições e possibilidades dos participantes, baseando-se nos seus próprios conceitos e critérios de explicação. Além do objetivo de impulsionar a autoanálise e a autodeterminação de grupos comunitários, o propósito do DRP é a obtenção direta de informação primária ou de campo na comunidade (VERDEJO, 2006). No presente trabalho, foram aplicadas entrevistas semiestruturadas e a travessia como ferramentas diagnósticas. Em seguida, realizou-se uma reunião informal, em roda de conversa, com os demais produtores associados para o levantamento de demandas, para fins de comparação com os problemas identificados nas propriedades visitadas e atendimento mais abrangente a toda a comunidade.

O processo de delineamento da ação de extensão foi realizado de maneira conjunta e participativa. Inicialmente, foram compiladas todas as informações e dados coletados nas propriedades e entrevistas. Em seguida, por um processo de priorização de problemas (VERDEJO, 2006) foram definidas as atividades a serem abordadas na ação, sendo definido, nesta ocasião, que seria a realização de um Dia de campo como ferramenta de comunicação, uma vez que possibilita a apresentação de uma série de atividades em um mesmo encontro. Definiu-se, em acordo com os produtores, a realização da ação na universidade, visando ao fortalecimento da confiança na instituição e comunidade acadêmica e da indissociabilidade entre o ensino, a pesquisa e a extensão. De acordo com Silva e Silva (2013), o dia de campo busca despertar o interesse e a aplicação mais rápida da tecnologia que está sendo apresentada. Os participantes vão adquirindo o conhecimento e descobrindo qual o melhor caminho a seguir em função das suas próprias necessidades no meio rural.

Face às inúmeras demandas da comunidade visitada, e posteriormente à definição das atividades prioritárias, o enfoque no Dia de campo foi dado às questões relacionadas à adubação orgânica, ao preparo de caldas visando ao manejo fitossanitário e às possibilidades de diversificação da produção e agregação de valor e renda. 
Na prática, foram instaladas duas estações de atendimento. A primeira, buscou demonstrar os procedimentos para uma compostagem termofílica em leiras estáticas com aeração passiva à realidade brasileira, denominado Método UFSC (BRASIL, 2017), e para utilização de uma composteira caseira, com escoamento e armazenamento de chorume, adaptado de Gotardo Filho et al. (2019). Em outra estação, demonstrou-se o preparo de caldas para controle de pragas e doenças em cultivo orgânico. Adicionalmente, os produtores realizaram uma visita técnica pelo Horto de Plantas Medicinais e Horta orgânica da UFGD, para que a eles fossem apresentadas opções de cultivos diferenciados visando à diversificação da sua produção.

Ao final da ação, os participantes responderam um questionário avaliativo para o feedback do projeto.

\section{RESULTADOS E DISCUSSÃO}

A identificação de demandas e gargalos para produção de alimentos orgânicos constitui o marco inicial de trabalho da extensão acerca do assunto. Nesse contexto, a utilização das metodologias participativas do DRP representa um verdadeiro avanço no campo e, de acordo com Souza (2009), proporciona a oportunidade de autoavaliação de si e da cultura do grupo a que pertence um indivíduo, capacidade reflexiva sobre os efeitos de vida cotidianas, capacidade de criar e recriar não somente objetivos materiais, mas, também, e, fundamentalmente, criar e recriar formas novas de vida e de convivência social.

Com base na concepção de DRP proposta por Verdejo (2006), o processo diagnóstico realizado na Agrovargas foi realizado em duas propriedades, selecionadas em comum acordo entre os produtores associados, que refletiam o panorama geral da comunidade em termos de produção e infraestrutura, com a participação da AGRAER/MS. Na primeira propriedade, a olericultura orgânica apresentava-se como atividade exclusiva de geração de renda; nesta destacam-se: o emprego de práticas conservacionistas, com baixo nível de degradação do solo, o uso exclusivo de práticas manuais, a mão-de-obra insuficiente, o baixo emprego de tecnologia, a diversidade de espécies olerícolas, porém, sem uso da rotação e consorciação de culturas. Já a outra propriedade apresentava atividades mais diversificadas além da olericultura orgânica, como a piscicultura e fruticultura; nesta propriedade, também se destacava o uso 
exclusivo de práticas manuais. Nesta última, além das atividades descritas, observou-se o cultivo de soja e milho convencionais como fonte primária de renda, cuja administração ficava sob a responsabilidade dos filhos do casal; este, por sua vez, se dedicava às demais atividades, resultando em mão-de-obra ainda mais insuficiente do que na propriedade anterior e na subutilização dos recursos disponíveis.

O diagnóstico nas propriedades foi ancorado em duas ferramentas principais visando compreender as atividades desenvolvidas na comunidade: as entrevistas semiestruturadas e a travessia (Figura 1A). As entrevistas desempenham um papel muito importante no DRP, sendo guiadas por perguntas-chave previamente determinadas e facilitando criar um ambiente aberto de diálogo, sem as limitações criadas por um questionário. A travessia foi realizada nas propriedades individuais; através de uma caminhada, os produtores eram estimulados suas rotinas, associando-a com o que estava à sua volta.

Após as visitas às propriedades, foi realizada uma discussão sobre todos os pontos visualizados com a participação de todos os associados, buscando-se também as demandas dos produtores não visitados, estabelecendo-se os temas prioritários para abordagem na ação de extensão futura (Figura 1B).
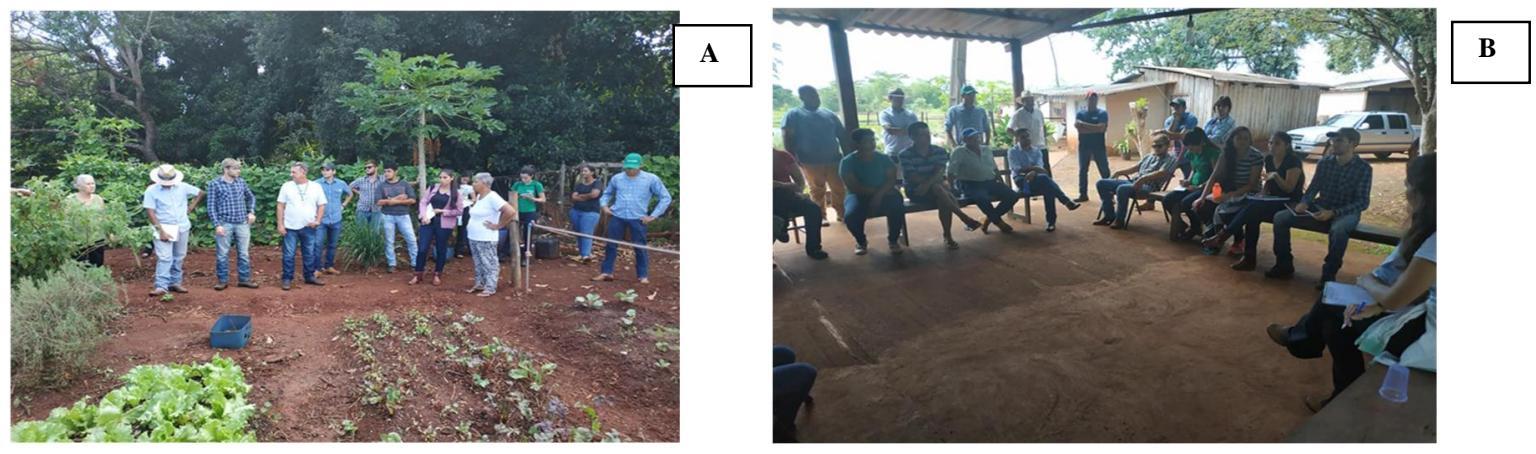

Figura 1. Aplicação dos métodos de DRP nas propriedades (A) e discussão com todos os membros da Agrovargas (B). Dourados-MS, 2019.

A partir dos principais levantamentos e demandas diretas dos produtores visitados, foi possível estabelecer uma priorização, ranqueando-se os problemas identificados durante o diagnóstico segundo sua importância e/ou urgência para a comunidade (VERDEJO, 2006). As demandas principais foram relacionadas ao manejo da produção orgânica visando a melhoria da oferta dos produtos e agregação de valor e 
renda visando ao fortalecimento da atividade na comunidade. Desse modo, com foco nos aspectos técnicos da produção, estabeleceu-se a abordagem dos temas no Dia de campo: a) adubação orgânica, b) controle de pragas e doenças em sistemas orgânicos e c) opções para diversificação da produção e geração de renda.

O Dia de Campo é um eficiente método de divulgação de tecnologias e práticas agropecuárias sustentáveis voltadas para o meio rural. Vem sendo usado, no Brasil, desde que o serviço de extensão rural foi implantado em 1948 (EMATER-RJ, 1996). É um método de comunicação grupal que permite a troca de conhecimento, desperta e motiva nos participantes o interesse em adotar novas práticas (CARVALHO; SOARES, 2006), razão pela qual foi o mais adequado para atender os produtores-alvo da ação. Da parte da comunidade atendida, foi um método de comunicação útil para a demonstração prática das atividades-alvo da ação extensionista.

A regulamentação da agricultura orgânica é disposta na Lei $\mathrm{n}^{\circ} 10.831$, de 23/12/2003, que visa estabelecer critérios para a produção e comercialização de produtos, definir responsabilidades pela qualidade orgânica, pelos procedimentos relativos à fiscalização, à aplicação de sanções, ao registro de insumos e à adoção de medidas sanitárias e fitossanitárias (HENZ et. al., 2007). Deste modo, todas as técnicas empregadas na produção orgânica devem atender aos critérios estabelecidos na Legislação brasileira.

Nesse contexto, a compostagem é um processo de degradação controlada de resíduos orgânicos sob condições aeróbias, ou seja, com a presença de oxigênio, no qual se procura reproduzir condições favoráveis à aceleração da transformação de resíduos de forma segura, favorecendo uma grande diversidade de macro e microrganismos, que, sucessiva ou simultaneamente, aceleram a decomposição orgânica (BRASIL, 2017). Segundo Couto et al. (2008), o composto orgânico pode ser utilizado com sucesso em hortas domésticas e comunitárias. Além de melhorar substancialmente o desenvolvimento das hortaliças, o composto melhora as propriedades físicas do solo porque aumenta a infiltração de água e a capacidade de retenção da água nos canteiros.

Dentre os métodos existentes, o Método UFSC, ou de compostagem termofílica em leiras estáticas com aeração passiva, tem se destacado quanto à simplicidade, à versatilidade e à vasta experiência acumulada em projetos de sucesso no Brasil, especialmente no contexto comunitário e institucional. Embora todo processo de

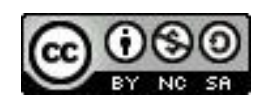


degradação de matéria orgânica na presença de oxigênio possa ser considerado como compostagem, a forma como diferentes fatores são combinados e controlados caracteriza diferentes métodos (BRASIL, 2017).

A abordagem do tema da compostagem vem de encontro à necessidade dos produtores visitados em manejarem de modo adequado todo o processo de produção de adubo orgânico, viabilizando a obtenção de um composto rico em nutrientes (Figura 2). Um composto bem feito apresenta matéria orgânica transformada em húmus e atua, no solo, melhorando sua estrutura e dando a ele condições de armazenar maior quantidade de água, de ar e de nutrientes, que alimentarão as plantas (LUCON; CHAVES, 2004).
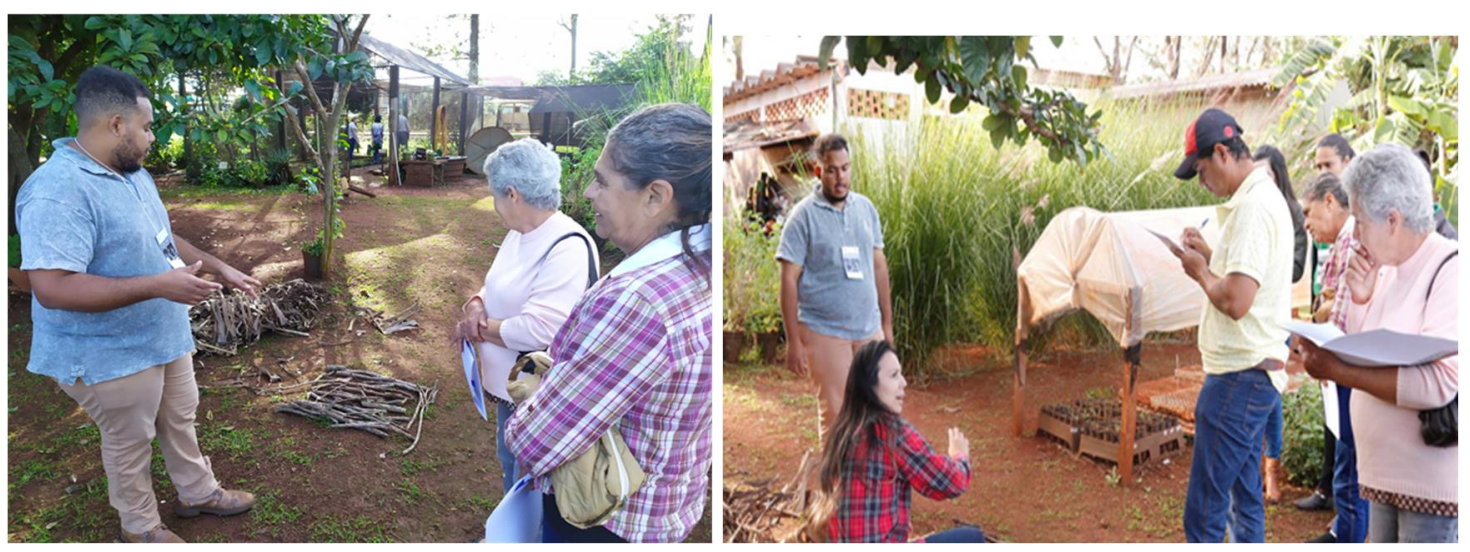

Figura 2. Apresentação sobre metodologia de compostagem termofílica em leiras estáticas com aeração passiva. Dourados-MS, 2019.

De modo análogo, a compostagem aeróbica caseira tem ganhado importância ao considerarmos que os resíduos orgânicos podem ser reciclados por processos relativamente simples e de baixo custo (BARREIRA et al., 2006). Processos domésticos de compostagem em pequena escala e em sistemas fechados são ainda pouco realizados. A maioria dos sistemas de compostagem no Brasil são realizados ao ar livre (VICH et al., 2017), como é, inclusive, o caso dos produtores participantes da ação de extensão.

Para o bom funcionamento de uma composteira doméstica, as quais são geralmente construídas com baldes ou caixas plásticas (Figura 3), deve-se ater aos resíduos que são permitidos e que, portanto, devem ou não ser adicionados para que o processo de decomposição microbiana seja adequadamente realizado (KIEHL, 2004). Além disso, assim como em sistemas abertos de compostagem, nos sistemas fechados, como de composteiras domésticas e, associado aos tipos de compostos orgânicos, outros 
fatores também interferem na eficiência do processo de decomposição, tais como a temperatura, a umidade (entre 50\% e 70\%), a aeração, a relação carbono/nitrogênio, o pH e a granulometria dos resíduos colocados, isso porque estes fatores irão influenciar na ação tanto dos microrganismos como das minhocas, no caso da vermicompostagem (CHANG et al, 2006; VALENTE et al., 2009).

Outro produto do processo é o biofertilizante, chamado também de chorume, resultante da decomposição de matéria orgânica, que pode ser utilizado como adubo ou pesticida. Deve-se, entretanto, atentar-se para o seu adequado controle e gerenciamento (KEMERICH et al., 2014; FERRI et al., 2015).

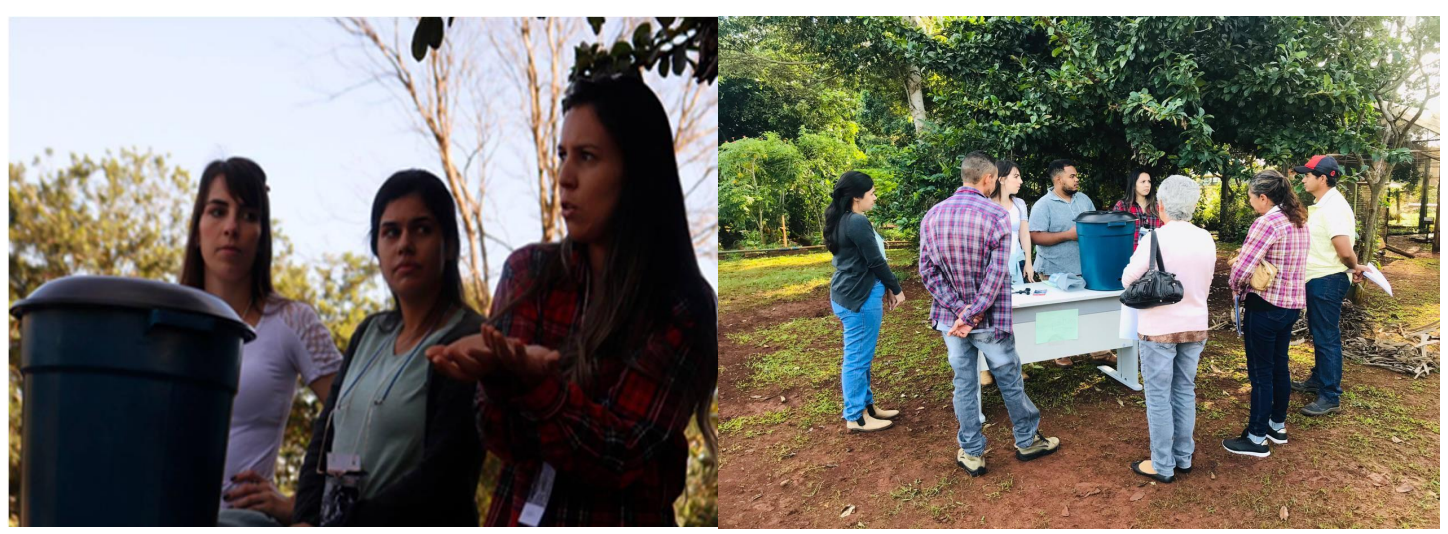

Figura 3. Apresentação sobre metodologia de compostagem aeróbica caseira. DouradosMS, 2019.

Em sistemas orgânicos de cultivo, o controle de pragas e doenças deve ser feito somente quando houver possibilidade de danos consideráveis à produção. Desse modo, o monitoramento sistemático de doenças e pragas em cultivo orgânico é que determinará a necessidade ou não de intervenção, que somente poderá ser feita com produtos permitidos pela legislação em vigor. De acordo com Penteado (2001), são considerados defensivos alternativos e naturais todos os produtos químicos, biológicos, orgânicos ou naturais, que apresentem as seguintes características: praticamente não tóxicos (grupo toxicológico IV), de baixa ou nenhuma agressividade ao homem e à natureza, eficientes no combate aos insetos e microrganismos nocivos, desfavoráveis à ocorrência de formas de resistência de pragas e microrganismos, de custo reduzido, de simplicidade de manejo e aplicação, disponibilidade do produto ou do material para aquisição. 
Apesar do grande interesse pelos citados métodos alternativos de controle, existem poucos produtos registrados, frente à grande quantidade de produtos naturais e de agentes biológicos de controle existentes. Diante disso, são muitas as dificuldades para atender à demanda dos produtores que praticam o sistema de produção orgânico, especialmente, em condições tropicais como no Brasil. Dentre os produtos naturais destacam-se a urina de vaca, o leite cru de vaca, os extratos de plantas (nim, alho e pimenta), os óleos essenciais e as caldas (bordalesa, viçosa e sulfocálcica). As caldas, além do controle fitossanitário, também aumentam a resistência das plantas às pragas, por adicionalmente consistirem em uma via importante de fornecimento de nutrientes (SOUZA; REZENDE, 2003; VENZON et al., 2010).

Os cuidados com a preparação das caldas incluem desde o uso de matéria prima de boa qualidade até a efetiva utilização no campo (Figura 4). Inclusive, recomenda-se que sejam feitas observações preliminares aplicando-se primeiramente em áreas reduzidas, considerando o local, clima e espécie, entre outros.

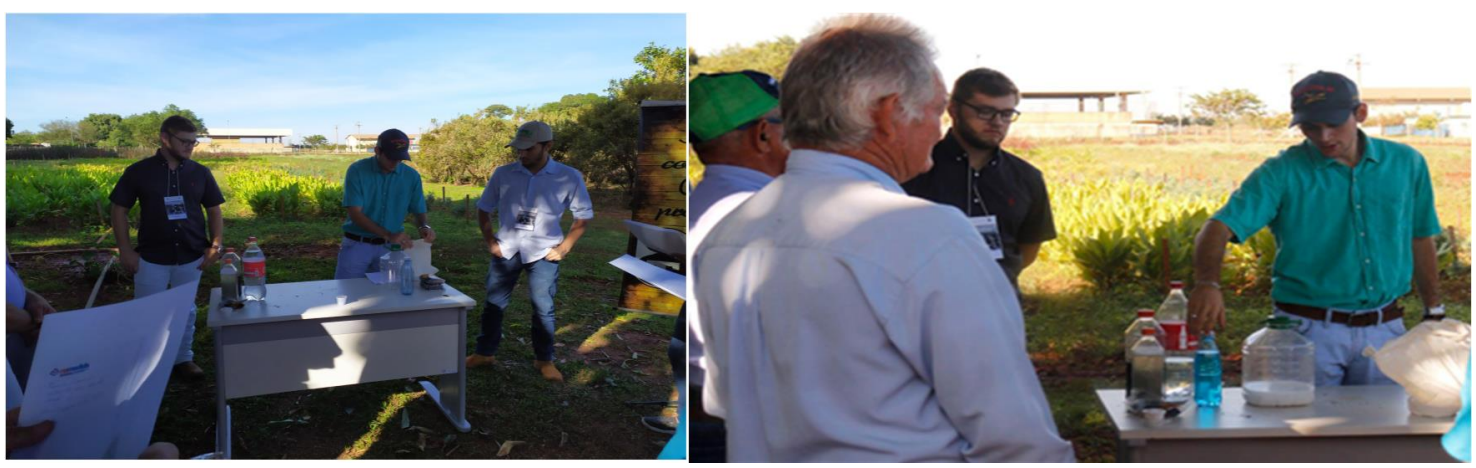

Figura 4. Elaboração de caldas ï extrato de fumo, cinza vegetal e calda bordalesa. Dourados-MS, 2019.

A utilização do extrato de fumo (Nicotiana tabacum) é recomendado para controle de pulgões, percevejos, vaquinhas, cochonilhas e grilos em plantas frutíferas e hortícolas; a aplicação deve ser feita com antecedência mínima de 12 dias da colheita para não deixar resíduo de nicotina nos alimentos. Existem várias maneiras de preparar as caldas, segundo Guerra (1985), Costa e Campanhola (1997), Abreu Júnior (1998) e Hamerschmidt (1999).

A calda de cinza e cal é um excelente produto para o controle de insetos como lagartas, vaquinhas, pulgões e pulga do fumo (HAMERSCHMIDT, 1999). Além da 
função de controlar insetos nocivos, a calda pode ser usada com vistas ao fornecimento de nutrientes importantes como cálcio, potássio e magnésio.

Em hortaliças e fruteiras, a calda bordalesa é recomendada para o controle de diversas doenças foliares. O seu uso é permitido na agricultura orgânica porque os seus componentes, sulfato de cobre e cal, são pouco tóxicos, além de contribuir para o equilíbrio nutricional das plantas, fornecendo cálcio e cobre (MOTA, 2008). O princípio desta calda não é erradicar patógenos, mas, sim, aumentar a resistência e a repelência das plantas.

As atividades agrícolas geralmente exploram poucas espécies, do ponto de vista comercial. Este paradoxo reforça a necessidade de pesquisas visando à melhor exploração da biodiversidade brasileira (GARCIA, 1995). Adicionalmente, a agricultura atual, com reduzida diversidade de espécies, caminha em direção à extinção de certos alimentos, com consequências no consumo de dietas ricas em nutrientes (MORATOYA et al., 2013).

As plantas alimentícias não convencionais (PANCs) estão entre as fontes de alimentos que se desenvolvem em ambientes naturais sem a necessidade de insumos e da derrubada de novas áreas (BRESSAN et al., 2011). O fato de muitas dessas plantas estarem em áreas manejadas por agricultores torna-se estratégia fundamental para o fortalecimento da soberania alimentar de muitas famílias (CRUZ-GARCIA; PRICE, 2011). Entretanto, muitas dessas plantas, embora disponíveis a baixo custo, ainda são desconhecidas e subutilizadas por uma parcela significativa da população (KINUPP et al., 2007; LUIZZA et al., 2013). Entre as PANCs que apresentam um mercado promissor, destacam-se o ora-pro-nobis, o gengibre, a araruta, o açafrão e o taro, espécies apresentadas aos produtores a fim de estimular a expansão da diversidade até então explorada (Figura 5).

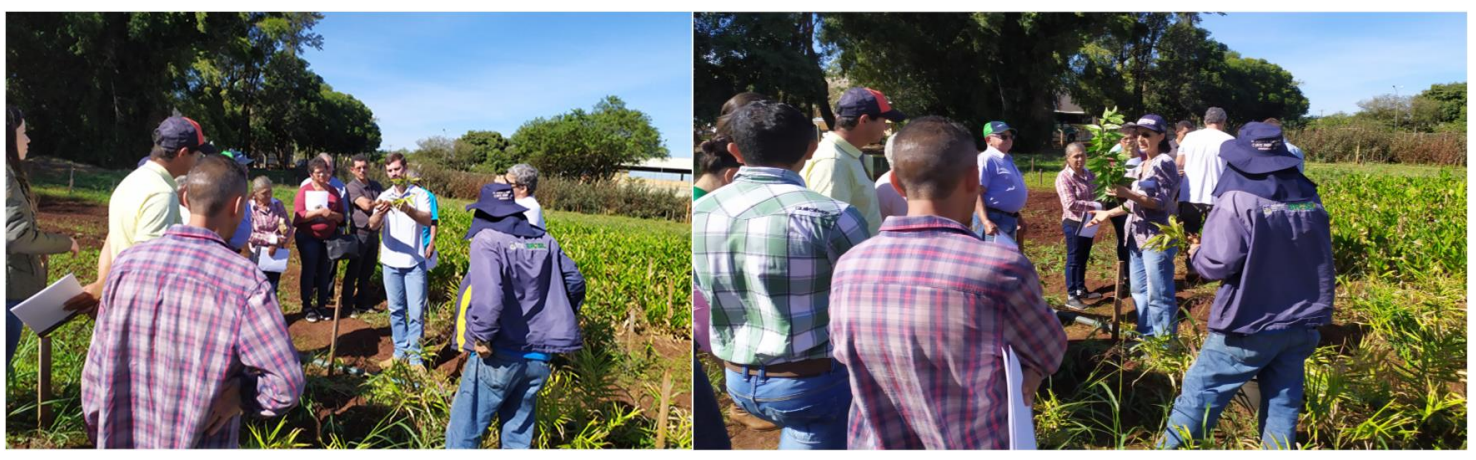

Figura 5. Área de cultivo de plantas alimentícias não convencionais. Dourados-MS, 2019.

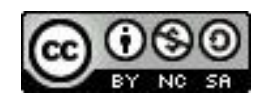


O ora-pro-nobis (Pereskia aculeata) é uma planta originária dos trópicos, pertencente à família das cactáceas. Devido às suas características e propriedades, esta planta representa uma alternativa para enriquecimento e incremento da qualidade da alimentação, pois suas folhas possuem importantes qualidades nutritivas, como alto teor de carboidrato, lisina, cálcio, fósforo, magnésio, ferro, cobre e, principalmente, alto teor de proteínas (ALMEIDA FILHO; CAMBRAIA 1974; CAMBRAIA, 1980; WANG et al. 1996; MERCÊ et al. 2001). Além disto, o ora-pro-nobis possui características agronômicas favoráveis ao seu cultivo, como o fato de ser uma planta rústica, vigorosa e de fácil propagação.

O gengibre (Zingiber officinale), planta da família Zingiberaceae, é originário do sudoeste asiático e amplamente comercializado em função de seu emprego na medicina popular e na alimentação (CORRÊA JUNIOR et al., 1994). É uma cultura com elevado potencial para a agricultura familiar, pelas características de seu sistema de produção e alta rentabilidade; enquanto o gengibre de melhor qualidade é destinado à exportação, o de menor tamanho pode ser comercializado no mercado interno (MENDES FERRÃO, 1993).

A araruta (Maranta arundinaceae) pertence à família Marantaceae, que teve seu centro de origem, provavelmente, no continente sul-americano. O rizoma fresco contém, conforme a idade da planta, mais de $20 \%$ de amido (PEREIRA et al., 1999). Como o preço alcançado pelo seu amido, no mercado internacional, é mais elevado que os similares, é grande o interesse dos industriais do setor na sua produção (MONTEIRO e PERESSIN, 2002).

O açafrão (Curcuma longa) é uma planta pertencente à família das Zingiberaceae, herbácea, perene, de folhas grandes e longas, e rizomas ovoides que, quando cortados, apresentam coloração amarelo avermelhado. A parte da planta comumente utilizada são os rizomas, empregados como corante alimentício, tempero ou condimento alimentar (BARNES et al., 2012).

O taro, cará ou, ainda, inhame (Dioscorea sp) é um alimento feculento, consumido principalmente em regiões tropicais, rico em carboidratos e vitaminas do complexo B. É uma opção viável para a agricultura familiar, devido à sua rusticidade, 
mediana exigência quanto à fertilidade do solo e maior tempo de conservação póscolheita.

As PANCs representam uma oportunidade para que produtores orgânicos possam atender determinados nichos de mercado, a fim de agregar valor e diversificar a sua produção. Nesse sentido, o primeiro passo é conhecer as características de cada espécie, a fim de empregar técnicas apropriadas de manejo.

As ações de extensão fortalecem o vínculo entre a universidade e a sociedade. Inúmeras ações pedagógicas têm proporcionado o maior aprendizado da comunidade acadêmica, ao mesmo tempo que beneficia produtores rurais, e promove a troca de conhecimento e saberes (MIRANDA et al., 2015; OLIVEIRA et al., 2016; OLIVEIRA et al., 2017). A ação refletiu de maneira clara a indissociabilidade entre ensino, pesquisa e extensão, uma vez que propiciou aos produtores rurais conhecer os resultados de trabalhos em andamento na universidade e que possuem aplicação prática em suas rotinas. Adicionalmente, a multidisciplinaridade de um Dia de campo possibilita a formação de uma rede de troca de informações unido vários atores em prol de um objetivo comum. Segundo Oliveira et al. (2017), a interdisciplinaridade depende fundamentalmente de uma atitude de colaboração frente ao desafio de uma prática coletiva, com o objetivo de se produzir conhecimento novo, unitário e crítico.

\section{CONCLUSÕES}

A difusão dos conteúdos explorados na ação de extensão gerou impacto positivo na comunidade, conforme os resultados do feedback aplicado, que revelou, quase em sua totalidade, o maior nível de satisfação possível. Nesse sentido, percebe-se que as ações que integram o ensino e a extensão contribuem sobremaneira para a melhoria do sistema de produção orgânica de hortaliças no âmbito da agricultura familiar.

\section{AGRADECIMENTOS}

À Agência de Desenvolvimento Agrário e Extensão Rural - Agraer/MS; à Pró Reitoria de Extensão e Cultura, da Universidade Federal da Grande Dourados, PROEX/UFGD; à Associação dos Produtores de Vila Vargas ï Agrovargas; e à equipe do Horto de Plantas Medicinais, da FCA/UFGD. 


\section{REFERÊNCIAS}

ABREU JUNIOR, H. de. Práticas alternativas de controle de pragas e doenças na agricultura: coletânea de receitas. Campinas: EMOPI, 1998.

ALMEIDA FILHO, J.; CAMBRAIA, J. Estudo do valor nutritivo do ñOra-pro-nobisò (Pereskia aculeata Mill.). Revista Ceres, v. 21, n. 114, p. 105-111, 1974.

ASSIS, R. L. Agricultura orgânica e agroecologia: questões conceituais e processo de conversão. Seropédica: Embrapa Agrobiologia, 2005.

BARNES, J.; ANDERSON, L. A.; PHILlIPSON, J. D. Fitoterápicos. 3. ed. Porto Alegre: Artmed, 2012.

BARREIRA, L. P.; PHILIPPI JUNIOR, A.; RODRIGUES, M. S. Usinas de compostagem do Estado de São Paulo: qualidade dos compostos e processos de produção. Engenharia Sanitária e Ambiental, v. 11, p. 385-393, 2006.

BRASIL. Ministério do Meio Ambiente. Compostagem doméstica, comunitária e institucional de resíduos orgânicos: manual de orientação. Brasília: MMA, 2017.

BRASIL. Ministério da Agricultura, Pecuária e Abastecimento. Produtos fitossanitários com uso aprovado para a agricultura orgânica. Disponível em: $<$ http://www.agricultura.gov.br/assuntos/sustentabilidade/organicos/produtos-fitossanita rios/produtos-fitossanitarios>. Acesso em: 26 ago. 2019.

BRESSAN, R. A. et al. Stress-adapted extremophiles provide energy without interference with food production. Food Security, v.3, n.1, p.93-105, 2011.

CAMBRAIA, J. Valor nutritivo do ñOra-pro-nobisò. Viçosa: UFV, 1980.

CARVALHO, M. A. T.; SOARES, M. H. P. Metodologia participativa de extensão rural para o desenvolvimento sustentável. Belo Horizonte: EMATER-MG, 2006.

CHANG, J. I.; TSAI, J. J.; WU, K. H. Composting of vegetable waste. Waste Management and Research, v. 24, p. 354ї 362, 2006.

CORRÊA JUNIOR, C.; MING, L. C.; SCHEFFER, M. C. Cultivo de plantas medicinais, condimentares e aromáticas. 2. ed. Jaboticabal: FUNEP, 1994.

COSTA, M. B. B. da; CAMPANHOLA. C. A agricultura alternativa no Estado de São Paulo. Jaguariúna: Embrapa Meio Ambiente, 1997.

COUTO, J. R. do; RESENDE, F. V. de; SOUZA, R. B. de; SAMINEZ, T. C. de O. Instruções práticas para produção de composto orgânico em pequenas propriedades. Brasília: Embrapa Hortaliças, 2008. 
CRUZ-GARCIA, G. S.; PRICE, L. L. Ethnobotanical investigation of ávildôfood plants used by rice farmers in Kalasin, Northeast Thailand. Journal of Ethnobiology and Ethnomedicine, v.7, n.33, p.1-20, 2011.

EMATER- RJ. Empresa de Assistência Técnica e Extensão Rural do Estado do Rio de Janeiro. Guia de metodologia de extensão rural. Rio de Janeiro: EMATER-RJ, 1996.

FERRI, G. L.; CHAVES, G. L. D.; RIBEIRO, G. M. Análise e localização de centros de armazenamento e triagem de resíduos sólidos urbanos para a rede de logística reversa: um estudo de caso no município de São Mateus, ES. Production, v. 25, n 1. p. 27-42. 2015 .

GABRIEL, A. M. A.; SOUZA, R.; OLIVEIRA, E. R.; ROSSINI, L. C.; MONÇÃO, F. P.; RAMOS, M. B. M.; GIMENES, L. S.; PEREIRA, T. L.; SILVA, E. C. P. Orientação em apiários no Assentamento Amparo, Dourados-MS. Realizaçãa, v. 2, n. 3, p. 36-41, 2015.

GARCIA, E. S. Biodiversidade, biotecnologia e saúde. Cadernos de Saúde Pública, v. 11, n. 3, p. 495-500, 1995.

GLIESSMAN, S. R. Agroecologia: processos ecológicos em agricultura sustentável. Porto Alegre: Editora da Universidade Federal do Rio Grande do Sul, 2000.

GOTARDO FILHO, C. Como montar uma composteira caseira: manual de orientação. Andradina: Secretaria Municipal de Meio Ambiente. 11p. Disponível em: <https://www.andradina.sp.gov.br/arquivos/31_arquivo_compostagem_.pdf>. Acesso em 26 ago. 2019.

GUERRA, M. S. Receituário caseiro: alternativas para o controle de pragas e doenças de plantas cultivadas e de seus produtos. Brasília: EMBRATER, 1985.

HAMERSCHMIDT, I. Manejo de pragas e doenças em sistemas orgânicos. Curitiba: EMATER-PR, 1999.

HENZ, G. P.; ALCÂNTARA, F. A. de; RESENDE, F. V. Produção orgânica de hortaliças: o produtor pergunta, a Embrapa responde. Brasília: Embrapa Informação Tecnológica Brasília, 2007.

JESUS, E. L. de. Histórico e filosofia da agricultura alternativa. Proposta, v. 27, p. 3440, 1985.

KEMERICH, P. D. C.; FLORES, C. E. B.; BORBA, W. F.; GERHARDT, A. E.; FLORES, B. A.; RODRIGUES, A. C.; BARROS, G. Indicativo de contaminação ambiental por metais pesados em aterro sanitário. Revista Monografias Ambientais. v. 13, n. 5, p. 3744-3755, 2014.

KIEHL, E. J. Manual de compostagem: maturação e qualidade do composto. 4. ed. Piracicaba: E. J. KIEL, 2004.

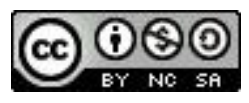


KINUPP, V. F.; BARROS, I. B. I. D. Riqueza de plantas alimentícias não-convencionais na Região Metropolitana de Porto Alegre, Rio Grande do Sul. Revista Brasileira de Biociências, v. 5, n. 1, p. 63-65, 2007.

LIMA, O. O. Gestão de riscos na Agricultura Orgânica. IN: SIMPÓSIO INTERNACIONAL EM GESTÃO AMBIENTAL E SAÚDE, 1., 2005, Santo Amaro. Anais. Santo Amaro: SENAC, 2005.

LIMA, P. C.; MOURA, W. M.; SEDIYAMA, M. A. N.; SANTOS, R. H. S.; MOREIRA, C. L. Manejo da adubação em sistemas orgânicos. In: LIMA, P.C.; MOURA, W. M.; VENZON, M.; PAULA Jr, T.; FONSECA, M. C. M. (Eds.). Tecnologias para produção orgânica. Viçosa: EPAMIG Zona da Mata, 2011. p.69-106.

LOPES, C. A. Controle de doenças de plantas na olericultura orgânica: qual o tamanho do desafio? Horticultura Brasileira, v. 30, n. 3, p. 565-565, 2012.

LUCON, C. M. M.; CHAVES, A. L. R. Horta Orgânica. Biológico, v. 66, p. 59-62, 2004.

LUIZZA, M. W. et al. Local knowledge of plants and their uses among women in the Bale Mountains, Ethiopia. Ethnobotany Research \& Applications, v. 11, n. 1, p. 31539, 2013.

MENDES FERRÃO, J. E. Especiarias: cultura, tecnologia, comércio. Lisboa: IICT, 1993.

MERCÊ, A. L. R. et al. Complexes of arabinogalactan of Pereskia aculeata and $\mathrm{Co}^{2+}$, $\mathrm{Cu}^{2+}, \mathrm{Mn}^{2+}$ and $\mathrm{Ni}^{2+}$. Bioresource Technology, v. 76, n. 1, p. 29-37, 2001.

MIRANDA, E.; SILVA, M. A. S. da; ROSAS, C. A. R. de F.; CUNHA, L. A. G. Aplicação de diagnóstico rural participativo (DRP) no Assentamento Três Lagoas ï Castro/PR: uma discussão sobre território e identidade. Geographia Opportuno Tempore, v. 1, n. 4, p. 36-46, 2015.

MONTEIRO, D. A.; PERESSIN, V. A. Cultura da araruta. In: CEREDA, M. P. (Coord.). Agricultura: tuberosas amiláceas Latino Americanas. São Paulo: Fundação Cargill, 2002. v. 2, p. 440-447.

MORATOYA, E. E.; CARVALHAES, G. C.; WANDER, A. E.; ALMEIDA, L. M. M. C. Mudanças no padrão de consumo alimentar no Brasil e no mundo. Revista de Política Agrícola, v. 22, n. 1, p. 72-84, 2013.

MOTA, I. de S. Calda bordalesa: utilidades e preparo. Dourados: Embrapa Agropecuária Oeste, 2008.

NEVES, M. C. P. Boas práticas agrícolas e a produção orgânica de frutas, legumes e verduras. Seropédica: Embrapa Agrobiologia, 2005. 
NEVES, M. C. P.; MEDEIROS, C. A. B.; ALMEIDA, D. L.; DE-POLLI, H.; RODRIGUES, H. R.; GUERRA, J. G. M.; NUNES, M. U. C.; CARDOSO, M. O.; AZEVEDO, M. S. F. R.; VIEIRA, R. C. M.; SAMINEZ, T. C. O. Agricultura orgânica: instrumento para a sustentabilidade dos sistemas de produção e valoração de produtos agropecuários. Seropédica: Embrapa Agrobiologia, 2000.

NEVES, M. C. P.; NEVES, J. F. Agricultura orgânica e produção integrada: diferenças e semelhanças. Seropédica: Embrapa Agrobiologia, 2007.

OLIVEIRA, E. R.; GABRIEL, A. M. A.; MONÇÃO, F. P.; FARIAS, M. F. L.; PEIXOTO, P. P. P.; RAMOS, M. B. M.; MOURA, L. V.; PEREIRA, T. L.; GANDRA, J. R.; SANTOS JUNIOR, E. A. Extensão universitária como estratégia de desenvolvimento na Comunidade Quilombola de Dourados/MS. Realização, v. 3, n.1, p. 35-44, 2016.

OLIVEIRA, E. R.; MONÇÃO, F. P.; RAMOS, M. B. M.; GABRIEL, A. M. A.; FARIAS, M. F. L.; MOURA, L. V. Práticas extensionistas no desenvolvimento sustentável da comunidade quilombola de Dourados, Mato Grosso do Sul. Em Extensão, v. 11, n. 2, p. 82-95, 2012.

OLIVEIRA, E. R.; MUNIZ, E. B.; GABRIEL, A. M. A.; MONÇÃO, F.; GANDRA, J. R.; GANDRA, E. R. de S.; PEREIRA, T. L.; SILVA, M. S. J. de; GOUVEA, W. S.; CARMO, A. A. do; PEDRINI, C. de A.; BECKER, R. A. S. Produção de feno orgânico como estratégia de suplementação volumosa para ruminantes produzidos nas comunidades rurais de Mato grosso do Sul. Realização, v. 4, n. 8, p. 87-97, 2017.

PEIXOTO, M. Extensão rural no Brasil: uma abordagem histórica da legislação. Brasília: Consultoria Legislativa do Senado Federal, 2008.

PENTEADO, S. R. Agricultura orgânica. Piracicaba: ESALQ, 2001.

PEREIRA, J.; CIACCO, C. F.; VILELA, E. R.; TEIXEIRA, L. de S. Fermented starch in the biscuit manufacturing: alternative sources. Ciência e Tecnologia de Alimentos, v. 19, n. 2, p. 287-293, 1999.

SILVA, A. P. G; SILVA, G. G. Planejando e executando o dia de campo. Recife: Instituto Agronômico de Pernambuco, 2013.

SOUZA, M. M. O. de. A utilização de metodologias de diagnóstico e planejamento participativo em assentamentos rurais: o diagnóstico rural/rápido participativo (DRP). Em Extensão, v. 8, n. 1, p. 34-47, 2009.

SOUZA, J. L.; RESENDE, P. Manual de horticultura orgânica. 2. ed. Viçosa, MG: Aprenda Fácil, 2003.

VALENTE B. S.; XAVIER E. G.; MORSELLI T. B. G. A.; JAHNKE D. S.; BRUM JR, B.S.; CABRERA B. R.; MORAES, P. O.; LOPES, D. C. N. Fatores que afetam o

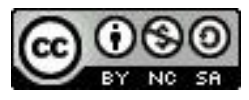


desenvolvimento da compostagem de resíduos orgânicos. Archivos de Zootecnia, v. 58, n. 1, p. 59-85. 2009.

VENZON, M.; OLIVEIRA, R. M.; BONOMO, I. S.; PEREZ, A. L.; RODRIGUEZCRUZ, F. A.; OLIVEIRA, J. M.; PALLINI, A. Manejo de ácaros-praga em sistemas orgânicos de produção. In: VENZON, M.; OLIVEIRA, R. M., BONOMO, I. S.; PEREZ, A. L.; RODRIGUEZ-CRUZ, F. A.; OLIVEIRA, J. M.; PALliNI, A. (Eds.) Controle alternativo de pragas e doenças na agricultura orgânica. Viçosa: EPAMIG, 2010. p.197-211.

VERDEJO, M. E. Diagnóstico Rural Participativo: um guia prático. Brasília: Secretaria da Agricultura Familiar SAF/MDA, 2006.

VICH, D. V.; MIYAMOTO, H. P; QUEIROZ, L. M.; ZANTA, V. M. Household foodwaste composting using a small-scale composter. Revista Ambiente \& Água, v. 12, n. 5 , p. $718-729.2017$.

WANG, S. H. et al. Características tecnológicas y sensoriales de fideos fortificados con diferentes niveles de harina de hojas de ora-pro-nobis (Pereskia aculeata Mill). Alimentaria, v. 276, n. 9, p. 91-96, 1996. 